\title{
BMJ Socio-demographic and other patient OPen characteristics associated with time between colonoscopy and surgery, and choice of treatment centre for colorectal cancer: a retrospective cohort study
}

\author{
David Goldsbury, ${ }^{1}$ Mark Fort Harris, ${ }^{2}$ Shane Pascoe,${ }^{2}$ Ian Olver, ${ }^{3}$ Michael Barton, ${ }^{4}$ \\ Allan Spigelman, ${ }^{5}$ Dianne O'Connell ${ }^{1}$
}

To cite: Goldsbury D, Harris MF, Pascoe S, et al. Socio-demographic and other patient characteristics associated with time between colonoscopy and surgery, and choice of treatment centre for colorectal cancer: a retrospective cohort study. BMJ Open 2012;2:e001070. doi:10.1136/

bmjopen-2012-001070

- Prepublication history for this paper is available online. To view this file please visit the journal online (http://dx. doi.org/10.1136/

bmjopen-2012-001070).

Received 1 March 2012 Accepted 3 May 2012

This final article is available for use under the terms of the Creative Commons Attribution Non-Commercial 2.0 Licence; see http://bmjopen.bmj.com

For numbered affiliations see end of article.

Correspondence to Dr David Goldsbury; davidg@nswcc.org.au

\section{ABSTRACT}

Objectives: To investigate key patient clinical and demographic characteristics associated with time between colonoscopy and surgery, and choice of treatment centre for colorectal cancer (CRC) patients. This will add to the little published research examining the pathway following CRC diagnosis and prior to surgery.

Design: Retrospective cohort analysis of linked data. Setting: A population-based sample of people diagnosed August 2004 to December 2007 in New South Wales, Australia.

Participants: 569 CRC patients, of whom 407 (72\%, $95 \% \mathrm{Cl} 68 \%$ to $75 \%$ ) had colonoscopy followed by surgery.

Primary outcome measures: Time between colonoscopy and surgery, and whether the surgery took place in a specialist cancer centre.

Results: Among the 407 eligible patients analysed, the median time from colonoscopy to surgery was 19 days (IQR 12-29 days). After adjusting for key demographic and clinical characteristics such as age and disease stage, the time was longer for rectal cancer patients and those reporting fair/poor health, although differences in medians were $<5$ days. $24 \%$ (95\% Cl $20 \%$ to $28 \%$ ) had surgery in a specialist cancer centre, which was more common among people resident in metropolitan areas (37\% vs $14 \%$ for others, adjusted $p=0.001)$ and those without private health insurance ( $30 \%$ vs $21 \%$ for others, adjusted $\mathrm{p}=0.03$ ).

Conclusions: There do not appear to be systemic issues affecting time from colonoscopy to surgery related to patients' socio-demographic characteristics. However, patients with private insurance and those living in rural areas may be less likely to receive optimal specialist treatment. A more systematic approach might be needed to ensure cancer patients are treated in specialist cancer centres, particularly patients requiring more specialised treatment.

\section{ARTICLE SUMMARY}

Article focus

- Investigate key patient clinical and demographic characteristics associated with time between colonoscopy and surgery, and choice of treatment centre for colorectal cancer patients in New South Wales, Australia.

- Most existing research has focused on delay prior to diagnosis, and little is known about factors associated with referral to specialist treatment following diagnosis.

Key messages

- Rectal cancer cases had slightly longer time to surgery than colon cancer cases.

- Treatment in a specialist cancer centre was associated more with patient access than disease characteristics.

- We need to ensure that those with the greatest need, such as those with rectal cancer, have access to timely and specialist treatment.

Strengths and limitations of this study

- This is one of the first studies to examine the pathway following colorectal cancer diagnosis and prior to surgery, with a relatively large population-based sample of patients.

- Surgery was the only treatment we could reliably analyse.

- Surgeon specialties were not known so specialist centres were identified as institutions with radiotherapy facilities.

- We cannot determine the exact reason for longer time to treatment and it might actually be a positive, possibly reflecting referral to a specialist surgeon or preoperative radiotherapy.

\section{INTRODUCTION}

Despite the availability of clinical guidelines, ${ }^{1}$ many colorectal cancer (CRC) patients do not receive optimal care. ${ }^{2}$ Two key aspects of optimal cancer care are the time between 
diagnosis and treatment ${ }^{3}{ }^{4}$ and receiving treatment in a specialist cancer centre. ${ }^{5-8}$

A recent systematic review found a significant relationship between hospital case volume and short-term mortality for cancer patients who receive surgery. ${ }^{9}$ However, inconsistencies in the findings mean that the relative importance of surgeon volume and hospital volume remains unclear and calls into question the usefulness of using case volume alone. ${ }^{9}$ Nevertheless, treatment in a specialist cancer treatment centre is important for patient care, especially for rectal cancer cases. $^{5-8}$

The time between diagnostic procedures and treatment is similarly important in terms of preventing disease progression and limiting patient psychological distress. ${ }^{3}$ This may be compounded by delays in diagnosis. Patient variables such as age, sex or socioeconomic status do not seem associated with delay. However, nonrecognition of symptom severity, symptom denial, having a regular general practitioner prior to receiving a cancer diagnosis, physician communication styles, receiving an initial alternate diagnosis, misdiagnosis, inadequate examination and inaccurate investigations all influence diagnostic delay. ${ }^{10}{ }^{11}$ A recent prospective study reported that 3-year mortality for CRC patients increased with diagnostic delay beyond 1 month, particularly for those presenting with serious symptoms. ${ }^{12}$ Past studies have also reported lower levels of CRC screening in Australia among groups such as migrants and people living in remote areas, ${ }^{13-15}$ indicating potential for further diagnostic delay for these groups. In Australia, the National Bowel Screening Program was introduced in 2006 with one-off testing for people turning 55 or 65 years, with people turning 50 years added in $2008 .^{16}$

The aim of this study was to use linked populationbased data to investigate factors associated with time between colonoscopy and surgery and choice of treatment centre for CRC cases in New South Wales (NSW), Australia.

\section{METHODS}

\section{Data sources}

Data used for the study comprised linked records from the population-based 45 and Up Study, the NSW Central Cancer Registry (CCR), the NSW Admitted Patient Data Collection (APDC) and claims for medical services from Medicare Australia.

The 45 and Up Study is a general population cohort study with over 265000 participants in NSW aged 45 years or more, representing around $10 \%$ of the population of that age. The study methods have been described in detail elsewhere. ${ }^{17}$ Briefly, participants were randomly selected from the Medicare Australia registration database, which covers all citizens and permanent residents of Australia. Baseline questionnaires were completed from January 2006 to April 2009, and participants gave consent to linkage to health data collections including the CCR, the APDC and Medicare claims records.
All cancers diagnosed in NSW, except for non-melanoma skin cancers, are notified to the NSW CCR. We obtained CCR records for people diagnosed with CRC between January 2001 and December 2007.

The NSW APDC contains information on all admitted hospital episodes in NSW. Hospital medical coders abstract individual patient information from medical records following the patient's discharge from hospital. Data include dates of admission and separation, procedures carried out and diagnoses relating to the hospital episode. Procedures were coded using the Medicare Benefits Schedule-Extended classification of the International Classification of Diseases 10th revision, Australian Modification (ICD-10-AM). Up to 50 procedure codes could be recorded for each episode. We used hospital separation records from July 2000 to June 2008.

Medicare data comprised claims for medical services through the Medicare Benefits Scheme (MBS) between June 2004 and January 2009. The MBS, a component of Australia's national health insurance system, provides subsidised access to medical services for Australian residents.

\section{Record linkage}

Identifying information for participants in the 45 and Up Study were linked with identifiers in the CCR, APDC hospital records and MBS claims. The linkage to the CCR and APDC was done by the Centre for Health Record Linkage ${ }^{18} \quad$ (CHeReL) using probabilistic matching carried out with ChoiceMaker software (ChoiceMaker Technologies Inc.). Both certain and uncertain matches were reviewed clerically, resulting in approximately $0.1 \%$ false-positive and $<0.1 \%$ falsenegative linkages. Linkage to MBS claims records was done by the Sax Institute using an encrypted version of the Medicare identification number. Ethical approval for the overall 45 and Up Study, this specific study and the linkage was given by the University of NSW Human Research Ethics Committee and the NSW Population and Health Services Research Ethics Committee. The provision of Medicare claims records was approved by the Department of Health and Ageing Ethics Committee.

\section{Subjects}

The group of interest comprised 45 and Up Study participants diagnosed with CRC who had a colonoscopy recorded in the APDC leading up to their diagnosis and surgical treatment after diagnosis. We restricted the sample to cases diagnosed from August 2004 to December 2007 who linked to both the APDC and MBS, so all cases had at least 2 months of treatments and consultations recorded prior to diagnosis and for at least 6 months after diagnosis.

\section{Socio-demographic and clinical characteristics}

The 45 and Up Study data included self-reported data regarding height, weight, highest education level 
attained, family history of CRC, smoking status, marital status, housing type, country of birth, language spoken at home, health insurance status (private with extras, private no extras, Department of Veterans Affairs/Healthcare card, none of these), income level (Australian dollars) and health status. Body mass index was calculated as weight (kilogram) divided by the square of height (metre). The CCR provided data regarding month and year of CRC diagnosis (the date of the most definitive cancer notification, likely to be based on the pathology form for the specimen obtained via colonoscopy), age at diagnosis, disease stage (classified as localised, regional spread, distant metastases or unknown), cancer site and local government area of residence at diagnosis from which we assigned quintiles of socioeconomic disadvantage. We identified patient comorbidities from APDC diagnosis codes, including cardiovascular disease, chronic obstructive pulmonary disease (COPD), diabetes and other diseases in the Charlson Comorbidity Index ${ }^{19}$ ('other key comorbidities').

\section{Procedures and consultations}

A specialist clinical panel (MFH, IO and MB) identified relevant procedure codes and items for colonoscopies and CRC surgery in the APDC and MBS data. Surgical treatment comprised hemicolectomies, total colectomies, partial colectomies, total proctocolectomies, anterior rectal resections, Hartmann's procedure (rectosigmoidectomy), abdominoperineal resections and 'other' resections of the colon or rectum. Chemotherapy and radiotherapy are generally performed on an outpatient basis, for which data were not available, so they were not included in the analysis.

Diagnosis dates were available as month and year only, so chronology around diagnosis was based on calendar month and year only. We included surgical procedures from the month of diagnosis onwards and the last presurgery colonoscopy no earlier than 2 months prior to the month of diagnosis. Actual dates of colonoscopy and surgery were used in analysing time between the procedures.

\section{Outcomes}

The primary outcomes of interest were the time between diagnosis and treatment and whether or not the patient received surgery in a specialist cancer centre, as defined by an institution having radiotherapy facilities. Colonoscopy was used as the indicator for diagnosis and an appropriate surgical procedure as the treatment. Over $90 \%$ of the relevant colonoscopies and surgical procedures were identified in the APDC, with just over half of these also identified in the MBS. The remaining colonoscopies were recorded in the MBS only.

\section{Statistical analysis}

$\chi^{2}$ Tests were used to compare patient groups, and unconditional multivariable logistic regression was used to identify factors associated with treatment in a specialist cancer centre. Cox's proportional hazards regression was used to investigate factors associated with time between colonoscopy and surgery. Factors of interest were patient characteristics including age, disease stage, place of residence and self-reported health status, as described in table 2. A small number of patients with missing values for variables of interest were excluded from analyses. All analyses were carried out in SAS V.9.1 (SAS Institute Inc.).

\section{RESULTS}

Baseline questionnaire data from the 45 and Up Study were received for the first 102938 study participants, with questionnaires completed between January 2006 and May 2008. These were linked to 1023 cases of CRC in the CCR. Among these 1023 cases, 1007 (98\%) linked to at least one APDC hospital record and 985 (96\%) linked to at least one MBS claim in the available data. The 1023 were compared with all CRCs diagnosed in NSW between 2001 and 2007 and a greater proportion of the study sample was men ( $62 \%$ vs $54 \%$ overall), Australian born $(76 \%$ vs $70 \%$ ), diagnosed in 2007 (22\% vs $16 \%$ ), had localised stage of disease $(42 \%$ vs $34 \%)$ or were living in rural areas $(34 \%$ vs $26 \%)$ or the two least socioeconomically disadvantaged quintiles $(50 \%$ vs $36 \%$ ), while a lower proportion were aged 80 years or more (15\% vs $23 \%)$, had distant metastases ( $7 \%$ vs $17 \%$ ), had any of the key comorbidities (32\% vs $41 \%)$ or were living in metropolitan areas ( $41 \%$ vs $51 \%)$.

The sample was restricted to the 569 CRC cases diagnosed from August 2004 to December 2007 who linked to both the APDC and MBS (figure 1). This represents $4 \%$ of all CRCs diagnosed in NSW between August 2004 and December 2007. We found that around $95 \%$ of surgical cases had their surgery within 3 months of diagnosis so the minimum 6 months of follow-up we have for all cases is reasonable (average follow-up: 25 months).

Of the 569 cases diagnosed from August 2004 to December 2007, 537 (94\%) had a colonoscopy recorded at any time and $488(86 \%)$ had surgery. There were 407

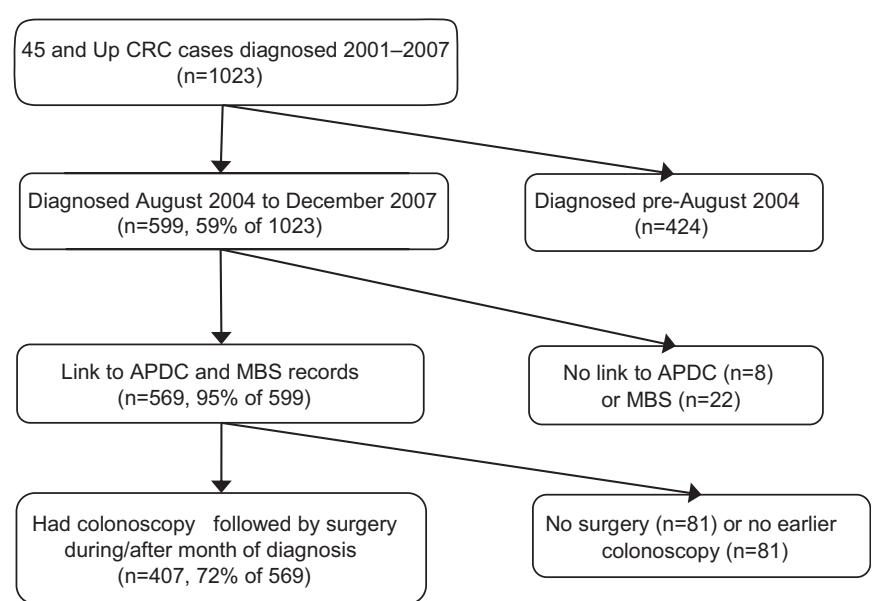

Figure 1 Sample selection process. APDC, Admitted Patient Data Collection; CRC, colorectal cancer; MBS, Medicare Benefits Scheme. 
Table 1 Characteristics of colorectal cancer cases included in the study and those not included in further analyses ( $\mathrm{n}=1023)$

\begin{tabular}{|c|c|c|c|c|c|}
\hline & \multicolumn{2}{|c|}{$\begin{array}{l}45 \text { and Up cases diagnosed, } \\
\text { August } 2004 \text { to December } \\
2007, \text { had colonoscopy and } \\
\text { surgery }(n=407)\end{array}$} & \multicolumn{2}{|c|}{$\begin{array}{l}\text { All other } 45 \text { and Up cases } \\
\text { diagnosed, January } 2001 \text { to } \\
\text { December } 2007(n=616)\end{array}$} & \multirow{2}{*}{$\begin{array}{l}p \text { value } \\
\text { for difference }\end{array}$} \\
\hline & No. of cases & $\%$ of cases & No. of cases & $\%$ of cases & \\
\hline \multicolumn{5}{|l|}{ Sex } & 0.72 \\
\hline Female & 152 & 37 & 237 & 38 & \\
\hline Male & 255 & 63 & 379 & 62 & \\
\hline \multicolumn{5}{|l|}{ Age at diagnosis (years) } & 0.08 \\
\hline$<60$ & 78 & 19 & 135 & 22 & \\
\hline $60-69$ & 108 & 27 & 193 & 31 & \\
\hline $70-79$ & 150 & 37 & 208 & 34 & \\
\hline $80+$ & 71 & 17 & 80 & 13 & \\
\hline \multicolumn{5}{|c|}{ Place of residence at diagnosis } & 0.02 \\
\hline Metropolitan & 186 & 46 & 234 & 38 & \\
\hline Other urban & 103 & 25 & 156 & 25 & \\
\hline Rural & 118 & 29 & 226 & 37 & \\
\hline \multicolumn{5}{|c|}{ Self-reported health status } & 0.58 \\
\hline Good to excellent & 307 & 75 & 447 & 73 & \\
\hline Fair/poor & 78 & 19 & 134 & 22 & \\
\hline Unspecified & 22 & 5 & 35 & 6 & \\
\hline \multicolumn{5}{|c|}{ Chronic obstructive pulmonary disorder* } & 0.20 \\
\hline Yes & 29 & 7 & 32 & 5 & \\
\hline No & 378 & 93 & 568 & 95 & \\
\hline \multicolumn{5}{|l|}{ Diabetes* } & 0.69 \\
\hline Yes & 50 & 12 & 71 & 12 & \\
\hline No & 357 & 88 & 529 & 88 & \\
\hline \multicolumn{5}{|l|}{ Cancer site } & 0.49 \\
\hline Colon & 265 & 65 & 414 & 67 & \\
\hline Rectum & 142 & 35 & 202 & 33 & \\
\hline \multicolumn{5}{|l|}{ Disease stage } & 0.003 \\
\hline Localised & 185 & 45 & 246 & 40 & \\
\hline Regional & 176 & 43 & 255 & 41 & \\
\hline Distant metastases & 27 & 7 & 48 & 8 & \\
\hline Unknown & 19 & 5 & 67 & 11 & \\
\hline \multicolumn{5}{|c|}{ Timing of colorectal cancer diagnosis relative to 45 and Up questionnaire } & $<0.001$ \\
\hline Before (prevalent) & 327 & 80 & 552 & 90 & \\
\hline After (incident) & 80 & 20 & 64 & 10 & \\
\hline
\end{tabular}

cases $(72 \%)$ who received surgery from the month of diagnosis onwards and had a colonoscopy beforehand (up to 2 months before the month of diagnosis). These are the cases in whom we were most interested. Table 1 shows that these 407 cases were similar to the 616 cases identified in the CCR but not included in the study, except for a higher proportion with localised disease ( $45 \%$ and $40 \%$, respectively), who lived in metropolitan areas at diagnosis $(46 \%$ and $38 \%$ ) or who were diagnosed with CRC after completing the 45 and Up Study questionnaire $(20 \%$ vs $10 \%)$.

\section{Time between colonoscopy and surgery}

The overall median time from colonoscopy to surgery was 19 days (IQR 12-29 days). After adjusting for all measured factors, the time from colonoscopy to surgery was significantly longer for cases with rectal cancer and cases reporting fair/poor health (table 2). Given the likely difference in treatment patterns for colon and rectal cancer cases, we analysed them separately. Among rectal cancer, there was shorter time to surgery for cases with COPD, Department of Veterans Affairs/Healthcare cards, good to excellent self-reported health, those living in a house (compared with flat/unit or elderly accommodation) and cases not living in rural areas (table 3). For cases with colon cancer, who should not require preoperative radiotherapy or chemotherapy, there were no major differences in the time to surgery across the subgroups compared. The period was marginally longer for cases with unknown disease stage, those with lower income and those with a comorbidity in the Charlson Index other than cardiovascular disease, COPD or 
Table 2 Demographic and clinical characteristics associated with time between colonoscopy and colorectal cancer surgery for all colorectal cancer cases $(n=407)$

\begin{tabular}{|c|c|c|c|c|c|}
\hline & $\mathbf{n}$ & $\begin{array}{l}\text { Median } \\
\text { time (days) }\end{array}$ & IQR (days) & $\begin{array}{l}\text { Adjusted } \\
\text { HR }(95 \% \mathrm{CI})^{\star}\end{array}$ & $\begin{array}{l}\text { Overall } \\
\text { p value } †\end{array}$ \\
\hline Sex & & & & & 0.25 \\
\hline Female & 152 & 19 & $12-28$ & $1.18(0.89$ to 1.58$)$ & \\
\hline Male & 255 & 20 & $12-31$ & 1.00 (ref) & \\
\hline Age (years) & & & & & 0.88 \\
\hline$<60$ & 78 & 17 & $8-29$ & 0.96 (0.68 to 1.37$)$ & \\
\hline $60-69$ & 108 & 19 & $13-32$ & $0.93(0.69$ to 1.26$)$ & \\
\hline $70-79$ & 150 & 21 & $12-29$ & 1.00 (ref) & \\
\hline $80+$ & 71 & 20 & $12-28$ & $1.10(0.77$ to 1.57$)$ & \\
\hline Country of birth & & & & & 0.64 \\
\hline Australia & 320 & 19 & $13-29$ & 1.00 (ref) & \\
\hline Other & 81 & 19 & $8-30$ & $0.93(0.67$ to 1.28$)$ & \\
\hline Unknown & 6 & 12 & $10-40$ & Not incl. & \\
\hline Non-English spoken at home & & & & & 0.20 \\
\hline Yes & 30 & 21 & $10-38$ & $1.38(0.84$ to 2.27$)$ & \\
\hline No & 377 & 19 & $12-29$ & 1.00 (ref) & \\
\hline Place of residence at diagnosis & & & & & 0.56 \\
\hline Metropolitan & 186 & 19 & $11-28$ & 1.00 (ref) & \\
\hline Other urban & 103 & 20 & $13-28$ & $1.16(0.77$ to 1.74$)$ & \\
\hline Rural & 118 & 20 & $11-33$ & $0.96(0.65$ to 1.43$)$ & \\
\hline Type of housing & & & & & 0.52 \\
\hline House & 296 & 19 & $12-29$ & 1.00 (ref) & \\
\hline Flat/unit & 50 & 19 & $10-29$ & $1.10(0.77$ to 1.59$)$ & \\
\hline House on farm & 28 & 21 & $12-48$ & 0.77 (0.49 to 1.23$)$ & \\
\hline Elderly accommodation & 26 & 22 & $17-42$ & $0.85(0.52$ to 1.37$)$ & \\
\hline Other/unspecified & 7 & 29 & $19-31$ & Not incl. & \\
\hline Socioeconomic status & & & & & 0.44 \\
\hline Least disadvantaged quintile & 143 & 17 & $11-28$ & 1.00 (ref) & \\
\hline Quintile 2 & 64 & 20 & $12-34$ & $0.88(0.57$ to 1.38$)$ & \\
\hline Middle quintile & 126 & 20 & $8-29$ & $1.17(0.76$ to 1.80$)$ & \\
\hline Quintile 4 & 58 & 22 & $14-33$ & $0.92(0.60$ to 1.41$)$ & \\
\hline Most disadvantaged quintile & 16 & 22 & $14-27$ & $1.32(0.66$ to 2.62$)$ & \\
\hline Highest education level attained & & & & & 0.59 \\
\hline No school certificate/other & 48 & 20 & $14-31$ & $0.99(0.67$ to 1.47$)$ & \\
\hline School/intermediate certificate & 102 & 22 & $16-33$ & 1.00 (ref) & \\
\hline Higher school/leaving certificate & 28 & 18 & $12-34$ & $1.02(0.63$ to 1.65$)$ & \\
\hline Trade/apprenticeship & 56 & 18 & $13-28$ & 1.43 (0.96 to 2.13$)$ & \\
\hline Certificate/diploma & 83 & 20 & $10-29$ & $1.03(0.74$ to 1.43$)$ & \\
\hline Uni degree or higher & 80 & 16 & $8-36$ & $1.02(0.71$ to 1.48$)$ & \\
\hline Unspecified & 10 & 13 & $3-22$ & Not incl. & \\
\hline Marital status & & & & & 0.18 \\
\hline Married/living as married & 288 & 18 & $11-28$ & 1.00 (ref) & \\
\hline Single/divorced/separated & 51 & 24 & $12-37$ & $0.93(0.64$ to 1.36$)$ & \\
\hline Widowed & 65 & 22 & $17-34$ & $0.72(0.51$ to 1.02$)$ & \\
\hline Unspecified & 3 & 20 & $9-21$ & Not incl. & \\
\hline Income level & & & & & 0.06 \\
\hline$<\$ 20 K$ p.a. & 112 & 21 & $14-31$ & 1.00 (ref) & \\
\hline$\$ 20 \mathrm{~K}-<\$ 40 \mathrm{~K}$ p.a. & 83 & 21 & $13-31$ & $0.97(0.67$ to 1.41$)$ & \\
\hline$\$ 40 \mathrm{~K}-<\$ 70 \mathrm{~K}$ p.a. & 62 & 18 & $9-35$ & $0.92(0.62$ to 1.36$)$ & \\
\hline$\$ 70 K+$ p.a. & 52 & 13 & $8-29$ & 1.59 (1.01 to 2.51$)$ & \\
\hline Unspecified & 98 & 19 & $13-28$ & $1.30(0.93$ to 1.81$)$ & \\
\hline Health insurance & & & & & 0.51 \\
\hline Private with extras & 190 & 18 & $9-28$ & 1.00 (ref) & \\
\hline Private no extras & 70 & 17 & $11-28$ & $1.13(0.83$ to 1.55$)$ & \\
\hline DVA/healthcare card & 101 & 21 & $14-29$ & $1.05(0.77$ to 1.44$)$ & \\
\hline None of these & 37 & 28 & $19-41$ & $0.76(0.50$ to 1.15$)$ & \\
\hline Missing & 9 & 25 & $16-28$ & $0.86(0.40$ to 1.86$)$ & \\
\hline
\end{tabular}




\begin{tabular}{|c|c|c|c|c|c|}
\hline & $\mathbf{n}$ & $\begin{array}{l}\text { Median } \\
\text { time (days) }\end{array}$ & IQR (days) & $\begin{array}{l}\text { Adjusted } \\
\text { HR }(95 \% \mathrm{Cl})^{\star}\end{array}$ & $\begin{array}{l}\text { Overall } \\
\text { p value } †\end{array}$ \\
\hline Body mass index & & & & & 0.15 \\
\hline Underweight/normal & 155 & 18 & $10-28$ & 1.00 (ref) & \\
\hline Overweight & 157 & 20 & $12-35$ & $0.80(0.61$ to 1.05$)$ & \\
\hline Obese/morbidly obese & 66 & 22 & $13-31$ & $0.92(0.65$ to 1.30$)$ & \\
\hline Null/not specified & 29 & 19 & $11-29$ & $0.62(0.38$ to 0.99$)$ & \\
\hline Smoking status & & & & & 0.52 \\
\hline Never-smoker & 203 & 19 & $10-29$ & 1.00 (ref) & \\
\hline Ever-smoker & 204 & 19 & $12-30$ & $1.08(0.85$ to 1.37$)$ & \\
\hline Self-reported health status & & & & & 0.02 \\
\hline Good to excellent & 307 & 18 & $11-29$ & 1.00 (ref) & \\
\hline Fair/poor & 78 & 21 & $15-40$ & $0.69(0.51$ to 0.95$)$ & \\
\hline Unspecified & 22 & 22 & $14-28$ & 0.59 (0.35 to 1.02$)$ & \\
\hline Cardiovascular disease & & & & & 0.37 \\
\hline Yes & 47 & 20 & $9-29$ & $0.84(0.57$ to 1.23$)$ & \\
\hline No & 360 & 19 & $12-30$ & 1.00 (ref) & \\
\hline $\begin{array}{l}\text { Chronic obstructive } \\
\text { pulmonary disease }\end{array}$ & & & & & 0.16 \\
\hline Yes & 29 & 20 & $11-27$ & $1.41(0.87$ to 2.27$)$ & \\
\hline No & 378 & 19 & $12-30$ & 1.00 (ref) & \\
\hline Diabetes & & & & & 0.93 \\
\hline Yes & 50 & 26 & $14-36$ & $1.02(0.70$ to 1.48$)$ & \\
\hline No & 357 & 19 & $11-29$ & 1.00 (ref) & \\
\hline Other key comorbidity & & & & & 0.25 \\
\hline Yes & 56 & 20 & $12-29$ & $1.22(0.87$ to 1.71$)$ & \\
\hline No & 351 & 19 & $12-30$ & 1.00 (ref) & \\
\hline Family history of CRC & & & & & 0.58 \\
\hline Yes & 75 & 20 & $13-33$ & $0.92(0.69$ to 1.23$)$ & \\
\hline No & 332 & 19 & $12-29$ & 1.00 (ref) & \\
\hline Disease stage & & & & & 0.18 \\
\hline Localised & 185 & 19 & $13-29$ & 1.00 (ref) & \\
\hline Regional & 176 & 19 & $10-29$ & $1.06(0.84$ to 1.35$)$ & \\
\hline Distant metastases & 27 & 20 & $12-39$ & 0.65 (0.39 to 1.09$)$ & \\
\hline Unknown & 19 & 35 & $13-48$ & $0.70(0.40$ to 1.23$)$ & \\
\hline Cancer site & & & & & $<0.001$ \\
\hline Colon & 265 & 18 & $10-27$ & 1.00 (ref) & \\
\hline Rectum & 142 & 22 & $14-37$ & $0.55(0.43$ to 0.71$)$ & \\
\hline Year of diagnosis & & & & & 0.88 \\
\hline 2004 & 43 & 19 & $9-26$ & $1.10(0.72$ to 1.67$)$ & \\
\hline 2005 & 113 & 19 & $12-29$ & 0.98 (0.73 to 1.32$)$ & \\
\hline 2006 & 111 & 21 & $14-32$ & 0.92 (0.69 to 1.23$)$ & \\
\hline 2007 & 140 & 18 & $11-32$ & 1.00 (ref) & \\
\hline $\begin{array}{l}\text { Timing of CRC diagnosis } \\
\text { relative to } 45 \text { and }\end{array}$ & & & & & 0.23 \\
\hline \multicolumn{6}{|l|}{ Up questionnaire } \\
\hline Before (prevalent) & 327 & 19 & $11-29$ & $1.21(0.89$ to 1.66$)$ & \\
\hline After (incident) & 80 & 21 & $14-31$ & 1.00 (ref) & \\
\hline
\end{tabular}

${ }^{*}$ Adjusted for all other variables in this table. $\mathrm{HR}<1$ indicates longer time between colonoscopy and surgery.

tOverall $p$ value from proportional hazards regression (ref): reference category.

CRC, colorectal cancer; DVA, Department of Veterans Affairs; Not incl., this category was not included in proportional hazards regression.

diabetes (table 3). Just over one-quarter of cases $(27 \%)$ had more than 28 days between colonoscopy and surgery; this was more common for rectal cancer cases ( $39 \%$ vs $21 \%$ of colon cases).

\section{Treatment in a specialist cancer centre}

Ninety-nine $(24 \%)$ of the 407 cases had their surgery in a specialist cancer centre. This was more frequent among those living in metropolitan areas, as well as for cases without private health insurance, those with one of the 'other' Charlson Index comorbidities and cases who were married or living with a partner (table 4). When all the factors of interest were included in the logistic regression place of residence, health insurance and other comorbidities remained significantly associated with treatment in a specialist centre. 
Table 3 Demographic and clinical characteristics associated with time between colonoscopy and colorectal cancer surgery, separately for colon and rectal cancer cases

\begin{tabular}{|c|c|c|c|c|}
\hline & \multicolumn{2}{|c|}{ Colon cancer $(n=265)$} & \multicolumn{2}{|c|}{ Rectal cancer $(n=142)$} \\
\hline & $\begin{array}{l}\text { Adjusted } \\
\mathrm{HR}^{*}(95 \% \mathrm{Cl})\end{array}$ & $\begin{array}{l}\text { Overall } \\
\mathbf{p} \text { value } \dagger\end{array}$ & $\begin{array}{l}\text { Adjusted } \\
\text { HR* }^{*}(95 \% \mathrm{Cl})\end{array}$ & $\begin{array}{l}\text { Overall } \\
\text { p value } f\end{array}$ \\
\hline Place of residence at diagnosis & & 0.77 & & 0.01 \\
\hline Metropolitan & 1.00 (ref) & & 1.00 (ref) & \\
\hline Other urban & $1.19(0.67$ to 2.10$)$ & & $1.55(0.72$ to 3.37$)$ & \\
\hline Rural & $1.21(0.71$ to 2.07$)$ & & $0.47(0.21$ to 1.09$)$ & \\
\hline Type of housing & & 0.49 & & 0.002 \\
\hline House & 1.00 (ref) & & 1.00 (ref) & \\
\hline Flat/unit & $1.18(0.74$ to 1.87$)$ & & $0.31(0.12$ to 0.82$)$ & \\
\hline House on farm & $1.65(0.84$ to 3.25$)$ & & $0.43(0.18$ to 1.03$)$ & \\
\hline Elderly accommodation & $1.07(0.55$ to 2.11$)$ & & $0.19(0.06$ to 0.61$)$ & \\
\hline Other/unspecified & Not incl. & & Not incl. & \\
\hline Income level & & 0.04 & & 0.06 \\
\hline$<\$ 20 K$ p.a. & 1.00 (ref) & & 1.00 (ref) & \\
\hline$\$ 20 \mathrm{~K}-<\$ 40 \mathrm{~K}$ p.a. & $0.77(0.46$ to 1.29$)$ & & $0.59(0.30$ to 1.17$)$ & \\
\hline$\$ 40 \mathrm{~K}-<\$ 70 \mathrm{~K}$ p.a. & $0.93(0.55$ to 1.57$)$ & & $0.43(0.18$ to 0.99$)$ & \\
\hline$\$ 70 K+$ p.a. & $1.85(1.01$ to 3.40$)$ & & $0.54(0.20$ to 1.43$)$ & \\
\hline Unspecified & $0.98(0.63$ to 1.52$)$ & & $1.24(0.62$ to 2.46$)$ & \\
\hline Health insurance & & 0.12 & & 0.02 \\
\hline Private with extras & 1.00 (ref) & & 1.00 (ref) & \\
\hline Private no extras & $0.80(0.52$ to 1.22$)$ & & $1.79(0.93$ to 3.45$)$ & \\
\hline DVA/healthcare card & 0.67 (0.46 to 0.98$)$ & & $3.33(1.59$ to 6.97$)$ & \\
\hline None of these & $0.53(0.29$ to 0.97$)$ & & $1.29(0.58$ to 2.90$)$ & \\
\hline Missing & $0.42(0.12$ to 1.42$)$ & & $0.99(0.28$ to 3.46$)$ & \\
\hline Self-reported health status & & 0.10 & & 0.004 \\
\hline Good to excellent & 1.00 (ref) & & 1.00 (ref) & \\
\hline Fair/poor & $0.64(0.42$ to 0.96$)$ & & $0.44(0.21$ to 0.92$)$ & \\
\hline Unspecified & $0.95(0.48$ to 1.89$)$ & & $0.23(0.07$ to 0.76$)$ & \\
\hline Chronic obstructive pulmonary disease & & 0.26 & & 0.004 \\
\hline Yes & $1.39(0.79$ to 2.44$)$ & & $6.39(1.80$ to 22.70$)$ & \\
\hline No & 1.00 (ref) & & 1.00 (ref) & \\
\hline Other key comorbidity & & 0.04 & & 0.06 \\
\hline Yes & $1.64(1.03$ to 2.59$)$ & & $2.14(0.97$ to 4.75$)$ & \\
\hline No & 1.00 (ref) & & 1.00 (ref) & \\
\hline Disease stage & & 0.05 & & 0.87 \\
\hline Localised & 1.00 (ref) & & 1.00 (ref) & \\
\hline Regional & $1.08(0.79$ to 1.47$)$ & & $1.03(0.64$ to 1.66$)$ & \\
\hline Distant metastases & $0.53(0.28$ to 1.02$)$ & & $1.39(0.47$ to 4.14$)$ & \\
\hline Unknown & $0.48(0.24$ to 0.97$)$ & & $0.65(0.17$ to 2.50$)$ & \\
\hline
\end{tabular}

There was no association with cancer site (colon/ rectum).

The significant factors were similar when colon and rectal cancer cases were analysed separately, although for colon cases, there were also higher odds of treatment in a specialist centre for cases not born in Australia (39\% vs $21 \%$ of Australian born) and those with distant or unknown disease stage (31\% vs $24 \%$ of locoregional). Looking at all hospital records and not just episodes involving CRC surgery, $41 \%$ of cases had any admission recorded at a specialist cancer centre. Around half of all surgical procedures took place in public hospitals, and these comprised almost two-thirds of surgical procedures in specialist cancer centres.

\section{DISCUSSION}

Rectal cancer cases had slightly longer time to surgery than colon cancer cases, even after adjustment for comorbidities, disadvantage and health status, but there was no evidence that rectal cancer cases were more likely to be treated at specialist cancer centres (those with a radiotherapy unit). Treatment in a specialist cancer 
Table 4 Demographic and clinical characteristics associated with receiving colorectal cancer surgery in a specialist cancer centre $(n=407)$

\begin{tabular}{|c|c|c|c|c|}
\hline & Total (n) & $\begin{array}{l}\text { Treatment in a specialist } \\
\text { cancer centre, } \mathbf{n}(\%)\end{array}$ & $\begin{array}{l}\text { Adjusted OR } \\
(95 \% \mathrm{Cl})^{\star}\end{array}$ & $\begin{array}{l}\text { Overall } \\
\text { p value } \uparrow\end{array}$ \\
\hline Sex & & & & 0.71 \\
\hline Female & 152 & $27(18)$ & $0.87(0.43$ to 1.79$)$ & \\
\hline Male & 255 & $72(28)$ & 1.00 (ref) & \\
\hline Age (years) & & & & 0.78 \\
\hline$<60$ & 78 & $17(22)$ & 0.67 (0.28 to 1.63$)$ & \\
\hline $60-69$ & 108 & $27(25)$ & 1.01 (0.48 to 2.10$)$ & \\
\hline $70-79$ & 150 & $33(22)$ & 1.00 (ref) & \\
\hline $80+$ & 71 & $22(31)$ & $1.13(0.45$ to 2.85$)$ & \\
\hline Country of birth & & & & 0.14 \\
\hline Australia & 320 & $68(21)$ & 1.00 (ref) & \\
\hline Other & 81 & $29(36)$ & $1.79(0.83$ to 3.90$)$ & \\
\hline Unknown & 6 & 2 (33) & Not incl. & \\
\hline Non-English spoken at home & & & & 0.25 \\
\hline Yes & 30 & $10(33)$ & $0.50(0.15$ to 1.62$)$ & \\
\hline No & 377 & $89(24)$ & 1.00 (ref) & \\
\hline Place of residence at diagnosis & & & & 0.001 \\
\hline Metropolitan & 186 & $68(37)$ & 1.00 (ref) & \\
\hline Other urban & 103 & $18(17)$ & $0.27(0.10$ to 0.73$)$ & \\
\hline Rural & 118 & $13(11)$ & $0.14(0.05$ to 0.40$)$ & \\
\hline Type of housing & & & & 0.07 \\
\hline House & 296 & $65(22)$ & 1.00 (ref) & \\
\hline Flat/unit & 50 & $20(40)$ & $2.52(1.06$ to 6.01$)$ & \\
\hline House on farm & 28 & 7 (25) & $3.08(0.95$ to 10.01$)$ & \\
\hline Elderly accommodation & 26 & 7 (27) & $1.78(0.49$ to 6.40$)$ & \\
\hline Other/unspecified & 7 & 0 & Not incl. & \\
\hline Socioeconomic status & & & & 0.46 \\
\hline Least disadvantaged quintile & 143 & $54(38)$ & 1.00 (ref) & \\
\hline Quintile 2 & 64 & $9(14)$ & $0.78(0.27$ to 2.29$)$ & \\
\hline Middle quintile & 126 & $26(21)$ & $1.23(0.45$ to 3.34$)$ & \\
\hline Quintile 4 & 58 & $9(16)$ & $0.52(0.18$ to 1.49$)$ & \\
\hline Most disadvantaged quintile & 16 & $1(6)$ & $0.35(0.03$ to 3.88$)$ & \\
\hline Highest education level attained & & & & 0.16 \\
\hline No school certificate/other & 48 & $14(29)$ & 3.69 (1.31 to 10.36$)$ & \\
\hline School/intermediate certificate & 102 & $16(16)$ & 1.00 (ref) & \\
\hline Higher school/leaving certificate & 28 & $6(21)$ & $1.10(0.29$ to 4.24$)$ & \\
\hline Trade/apprenticeship & 56 & $15(27)$ & $1.84(0.69$ to 4.94$)$ & \\
\hline Certificate/diploma & 83 & $23(28)$ & $2.34(0.96$ to 5.68$)$ & \\
\hline Uni degree or higher & 80 & $23(29)$ & 1.69 (0.64 to 4.47$)$ & \\
\hline Unspecified & 10 & $2(20)$ & Not incl. & \\
\hline Marital status & & & & 0.10 \\
\hline Married/living as married & 288 & $75(26)$ & 1.00 (ref) & \\
\hline Single/divorced/separated & 51 & $12(24)$ & $0.53(0.21$ to 1.35$)$ & \\
\hline Widowed & 65 & $12(18)$ & $0.39(0.15$ to 1.01$)$ & \\
\hline Unspecified & 3 & 0 & Not incl. & \\
\hline Income level & & & & 0.74 \\
\hline$<\$ 20 K$ p.a. & 112 & $27(24)$ & 1.00 (ref) & \\
\hline$\$ 20 \mathrm{~K}-<\$ 40 \mathrm{~K}$ p.a. & 83 & $15(18)$ & $1.23(0.47$ to 3.24$)$ & \\
\hline$\$ 40 \mathrm{~K}-<\$ 70 \mathrm{~K}$ p.a. & 62 & $17(27)$ & $1.45(0.54$ to 3.91$)$ & \\
\hline$\$ 70 K+$ p.a. & 52 & 19 (37) & $2.10(0.71$ to 6.19$)$ & \\
\hline Unspecified & 98 & $21(21)$ & $1.33(0.56$ to 3.16$)$ & \\
\hline Health insurance & & & & 0.03 \\
\hline Private with extras & 190 & $44(23)$ & 1.00 (ref) & \\
\hline Private no extras & 70 & $10(14)$ & $0.72(0.29$ to 1.77$)$ & \\
\hline DVA/healthcare card & 101 & 29 (29) & 2.17 (0.97 to 4.89$)$ & \\
\hline None of these & 37 & $12(32)$ & 2.75 (0.99 to 7.62$)$ & \\
\hline Missing & 9 & $4(44)$ & 7.41 (1.17 to 47.04$)$ & \\
\hline
\end{tabular}




\begin{tabular}{|c|c|c|c|c|}
\hline & Total $(n)$ & $\begin{array}{l}\text { Treatment in a specialist } \\
\text { cancer centre, } \mathrm{n}(\%)\end{array}$ & $\begin{array}{l}\text { Adjusted OR } \\
(95 \% \mathrm{Cl})^{\star}\end{array}$ & $\begin{array}{l}\text { Overall } \\
\text { p value } †\end{array}$ \\
\hline Body mass index & & & & 0.78 \\
\hline Underweight/normal & 155 & $41(26)$ & 1.00 (ref) & \\
\hline Overweight & 157 & $39(25)$ & $1.02(0.53$ to 1.97$)$ & \\
\hline Obese/morbidly obese & 66 & $12(18)$ & 0.80 (0.33 to 1.93$)$ & \\
\hline Null/not specified & 29 & $7(24)$ & $0.59(0.18$ to 1.97$)$ & \\
\hline Smoking status & & & & 0.90 \\
\hline Never-smoker & 203 & $45(22)$ & 1.00 (ref) & \\
\hline Ever-smoker & 204 & $54(26)$ & $1.04(0.57$ to 1.89$)$ & \\
\hline Self-reported health status & & & & 0.19 \\
\hline Good to excellent & 307 & $77(25)$ & 1.00 (ref) & \\
\hline Fair/poor & 78 & $17(22)$ & $0.55(0.25$ to 1.25$)$ & \\
\hline Unspecified & 22 & $5(23)$ & $0.36(0.08$ to 1.65$)$ & \\
\hline Cardiovascular disease & & & & 0.61 \\
\hline Yes & 47 & $13(28)$ & 0.78 (0.30 to 2.02$)$ & \\
\hline No & 360 & $86(24)$ & 1.00 (ref) & \\
\hline Chronic obstructive pulmonary disease & & & & 0.64 \\
\hline Yes & 29 & $10(34)$ & $1.29(0.44$ to 3.82$)$ & \\
\hline No & 378 & $89(24)$ & 1.00 (ref) & \\
\hline Diabetes & & & & 0.15 \\
\hline Yes & 50 & $17(34)$ & $1.88(0.79$ to 4.50$)$ & \\
\hline No & 357 & $82(23)$ & 1.00 (ref) & \\
\hline Other key comorbidity & & & & 0.04 \\
\hline Yes & 56 & $19(34)$ & $2.43(1.04$ to 5.68$)$ & \\
\hline No & 351 & $80(23)$ & 1.00 (ref) & \\
\hline Family history of CRC & & & & 0.85 \\
\hline Yes & 75 & $19(25)$ & $0.93(0.44$ to 1.96$)$ & \\
\hline No & 332 & $80(24)$ & 1.00 (ref) & \\
\hline Disease stage & & & & 0.55 \\
\hline Localised & 185 & $41(22)$ & 1.00 (ref) & \\
\hline Regional & 176 & $45(26)$ & $1.34(0.72$ to 2.47$)$ & \\
\hline Distant metastases & 27 & 9 (33) & $2.02(0.63$ to 6.47$)$ & \\
\hline Unknown & 19 & $4(21)$ & $1.89(0.44$ to 8.20$)$ & \\
\hline Cancer site & & & & 0.64 \\
\hline Colon & 265 & $66(25)$ & 1.00 (ref) & \\
\hline Rectum & 142 & $33(23)$ & $1.16(0.63$ to 2.16$)$ & \\
\hline Year of diagnosis & & & & 0.11 \\
\hline 2004 & 43 & $10(23)$ & $1.00(0.36$ to 2.80$)$ & \\
\hline 2005 & 113 & $24(21)$ & $0.40(0.19$ to 0.88$)$ & \\
\hline 2006 & 111 & $27(24)$ & $0.88(0.43$ to 1.81$)$ & \\
\hline 2007 & 140 & $38(27)$ & 1.00 (ref) & \\
\hline $\begin{array}{l}\text { Timing of CRC diagnosis relative } \\
\text { to } 45 \text { and Up questionnaire }\end{array}$ & & & & 0.98 \\
\hline Before (prevalent) & 327 & $76(23)$ & $1.01(0.47$ to 2.19$)$ & \\
\hline After (incident) & 80 & $23(29)$ & 1.00 (ref) & \\
\hline
\end{tabular}

centre seems associated more with patient access than disease characteristics as the only strongly significant factor was residing in a non-metropolitan area. These results add further evidence for the disadvantage suffered by rural people in terms of their access to cancer treatment and are consistent with findings from New Zealand for the Maori population. ${ }^{20}$ Poor access may be one contributing factor to poorer cancer survival. ${ }^{21} 22$

The longer time from colonoscopy to surgery for rectal cancer cases compared with colon cancer cases is not necessarily a negative finding, given the additional importance of specialist treatment for rectal cancer. It may reflect referral to a CRC surgeon rather than a general surgeon, assessment by a multidisciplinary team, or the use of, or a referral for assessment for, preoperative radiotherapy for rectal cancer, each of which could lead to better patient outcomes. Furthermore, the crude difference in median time was only 4 days, which is not a clinically important difference in terms of disease progression, although it might add to 
patient distress. Analysis by disease site found that while there were some statistically significant differences in time between colonoscopy and surgery, the median differences were again in the order of a few days and thus not critical to disease progression. However, we should be mindful that these small delays may compound delays in diagnosis for groups, such as migrants and people living in remote areas who have lower screening rates ${ }^{13-15}$ and that diagnostic delay is associated with increased mortality for patients with CRC. ${ }^{12}$ The overall median time to surgery for all cases was 19 days and this could also be important in the context of additional delays along the total diagnostic pathway. It is also worth noting the proportion of rectal cases with more than a month between diagnosis and surgery was almost double that of colon cases. This was unrelated to issues such as private insurance but may be related to the pathway for treatment prior to surgery, including pre-surgical radiotherapy.

Treatment in a specialist cancer centre was associated with place of residence, health insurance status and the presence of comorbidities. Around one in four CRC patients had their surgery in a specialist cancer centre, while less than half were ever admitted to a specialist cancer centre. The results suggest that access plays a major role in place of treatment rather than the potentially more important disease characteristics. Rectal cancer patients in particular should be more commonly treated at specialist cancer centres ${ }^{5-7}$ or at least be referred to a multidisciplinary team for consideration for radiotherapy even if they are not in a radiotherapy centre. Private patients may be at a disadvantage in being referred to smaller private hospitals for their surgical procedures.

The study has some limitations. Our initial plan was to link CCR, APDC and MBS records for all CRC cases diagnosed over a number of years, but MBS data could not be released without the consent of each individual and this was not feasible. Using the data from the 45 and Up Study meant that the relevant consent had already been given, but this might introduce some biases as study participants are not representative of the population due to people in rural areas being oversampled and a possible 'healthy volunteer' effect. Our sample of cancer patients represent $4 \%$ of all CRCs diagnosed in NSW and were also more likely to be men, Australian born and have localised disease. However, the study's population coverage was still reasonably broad and it has been shown that the sample profile does not substantially impact on associations within the data. ${ }^{23}$ Some of the marginally statistically significant associations may have arisen by chance due to the large number of variables included in the analyses, but this is not likely to be an explanation for associations with small $p$ values.

Furthermore, we did not have access to surgeon information or temporal surgeon specialty lists in the almost 100 treating institutions included in the study, so specialist cancer centres were identified as institutions with radiotherapy facilities. We believe that our findings address an important component of cancer treatment and separate analyses of the distance from the treating centre to radiotherapy facilities obtained similar results. Treatment with chemotherapy or radiotherapy was not included as the available data were not comprehensive for all people receiving these treatments. Finally, the National Bowel Screening Program commenced in August 2006, screening people aged 55 and 65 years, ${ }^{16}$ so our results do not fully address what happens in the presence of the screening programme. However, the study is population-based, reasonably large and uses reliable surgical information ${ }^{24}$ and is an important addition to the literature on the subject.

\section{CONCLUSIONS}

Despite considerable research on the delay between screening and colonoscopy, the study is one of the first to examine the pathway following diagnosis and prior to surgery. There do not appear to be systemic issues affecting time from colonoscopy to surgery related to patients' socio-demographic characteristics. However, a more systematic approach might be needed to ensure that cancer patients are treated in specialist cancer centres, particularly for cases requiring more specialised treatment.

\section{Author affiliations}

${ }^{1}$ Cancer Epidemiology Research Unit, Cancer Council NSW, Sydney, Australia ${ }^{2}$ UNSW Research Centre for Primary Health Care and Equity, Sydney, Australia

${ }^{3}$ Cancer Council Australia, Sydney, Australia

${ }^{4}$ Collaboration for Cancer Outcomes Research and Evaluation, Liverpool Health Service, Sydney, Australia

${ }^{5}$ UNSW St Vincent's Clinical School, Sydney, Australia

Acknowledgements This research was completed using data collected through the 45 and Up Study (http://www.45andUp.org.au). The 45 and Up Study is managed by the Sax Institute in collaboration with major partner Cancer Council New South Wales; and partners the National Heart Foundation (NSW Division); NSW Health; beyondblue: the national depression initiative; Ageing, Disability and Home Care, NSW Department of Human Services and Uniting Care Ageing. We thank the many thousands of people participating in the 45 and Up Study. We thank the NSW Central Cancer Registry, the NSW Department of Health and Medicare Australia for making data available for analysis, and the NSW Centre for Health Record Linkage for conducting record linkage. We also thank the other members of the Colorectal Cancer Referral Pathways Study Team: Craig Veitch, John Stubbs, Justin Bielby, Lisa Crossland, Rohan Gett and David Weller.

Contributors DO and MFH contributed to conception and study design, participated in its coordination, advised on the data analysis and helped to draft the manuscript. DG assisted with obtaining the data and data management, undertook the analysis and drafted the manuscript. SP, I0, MB and AS contributed to conception and study design, participated in its coordination and helped to draft the manuscript. All authors read and approved the final manuscript.

Funding This work was supported by Cancer Australia (2007; Priority-driven Collaborative Cancer Research Scheme [510348]).

\section{Competing interests None.}

Ethics approval Ethical approval was provided by the University of New South Wales Human Research Ethics Committee and the New South Wales Population and Health Services Research Ethics Committee.

Provenance and peer review Not commissioned; externally peer reviewed.

Data sharing statement There are no additional data available. 


\section{REFERENCES}

1. Australian Cancer Network Colorectal Cancer Guidelines Revision Committee. Clinical Practice Guidelines for the Prevention, Early Detection and Management of Colorectal Cancer. Canberra, Australia: NHMRC, 2005

2. Spigelman AD. People with colorectal cancer: can we help them do better? (Editorial). Aust N Z J Surg 2004;74:401-2.

3. Risberg T, Sorbye SW, Norum J, et al. Diagnostic delay causes more psychological distress in female than in male cancer patients. Anticancer Res 1996;16:995-9.

4. Sorbye SW, Risberg T, Norum J, et al. [Cancer patients' perception of the examination period prior to treatment]. Tidsskr Nor Laegeforen 1998;118:2468-70.

5. Schrag D, Panageas KS, Riedel E, et al. Hospital and surgeon procedure volume as predictors of outcome following rectal cancer resection. Ann Surg 2002;236:583-92.

6. Smith JA, King PM, Lane RH, et al. Evidence of the effect of 'specialization' on the management, surgical outcome and survival from colorectal cancer in Wessex. Br J Surg 2003:90:583-92.

7. McArdle CS, Hole DJ. Influence of volume and specialization on survival following surgery for colorectal cancer. Br J Surg 2004;91:610-17.

8. Brannstrom $F$, Jestin $P$, Matthiesen $P$, et al. Surgeon and hospitalrelated risk factors in colorectal cancer surgery. Colorectal Dis 2011;13:1370-6.

9. Gruen RL, Pitt V, Green S, et al. The effect of provider case volume on cancer mortality: systematic review and meta-analysis. CA Cancer J Clin 2009;59:192-211.

10. Mitchell E, Macdonald S, Campbell NC, et al. Influences on prehospital delay in the diagnosis of colorectal cancer: a systematic review. Br J Cancer 2008;98:60-70.

11. Siminoff LA, Rogers HL, Thomson MD, et al. Doctor, what's wrong with me? Factors that delay the diagnosis of colorectal cancer. Patient Educ Couns 2011;84:352-8.

12. Torring ML, Frydenberg M, Hansen RP, et al. Time to diagnosis and mortality in colorectal cancer: a cohort study in primary care. $\mathrm{Br}$ Cancer 2011;104:934-40.

13. Weber MF, Banks E, Ward R, et al. Population characteristics related to colorectal cancer testing in New South Wales, Australia: results from the 45 and Up Study cohort. J Med Screen 2008;15:137-42.
14. Weber MF, Banks E, Smith DP, et al. Cancer screening among migrants in an Australian cohort; cross-sectional analyses from the 45 and Up Study. BMC Public Health 2009;9:144.

15. Ward PR, Javanparast S, Matt MA, et al. Equity of colorectal cancer screening: cross-sectional analysis of National Bowel Cancer Screening Program data for South Australia. Aust N Z J Public Health 2011;35:61-5

16. National Bowel Cancer Screening Program. Australian Government Department of Health and Ageing. Canberra, Australia. Last updated 8 November 2011. http://www.cancerscreening.gov.au/internet/ screening/publishing.nst/Content/bowel-about (accessed 20 Jan 2012).

17. Banks E, Redman S, Jorm L, et al. Cohort profile: the 45 and up study. Int J Epidemiol 2008;37:941-7.

18. CHeReL. Centre for Health Record Linkage. Sydney, Australia. http:// www.cherel.org.au (accessed 20 Jan 2012)

19. Charlson ME, Pompei $\mathrm{P}$, Ales $\mathrm{KL}$, et al. A new method of classifying prognostic comorbidity in longitudinal studies: development and validation. J Chronic Dis 1987;40:373-83.

20. Hill S, Sarfati D, Blakely T, et al. Survival disparities in Indigenous and non-Indigenous New Zealanders with colon cancer: the role of patient comorbidity, treatment and health service factors. J Epidemiol Community Health 2010;64:117-23.

21. Jong KE, Smith DP, Yu XQ, et al. Remoteness of residence and survival from cancer in New South Wales. Med J Aust 2004; 180:618-22.

22. Australian Institute of Health and Welfare, Cancer Australia and Australian Association of Cancer Registries. Cancer Survival and Prevalence in Australia: Cancers Diagnosed from 1982 to 2004 Cancer series no. 42. Canberra, Australia: AlHW, 2008. Cat. no. CAN 38

23. Mealing N, Banks E, Jorm L, et al. Investigation of relative risk estimates from studies of the same population with contrasting response rates and designs. BMC Med Res Methodol 2010;10:26.

24. Goldsbury DE, Smith DP, Armstrong BK, et al. Using linked routinely collected health data to describe prostate cancer treatment in New South Wales, Australia: a validation study. BMC Health Serv Res 2011;11:253. 